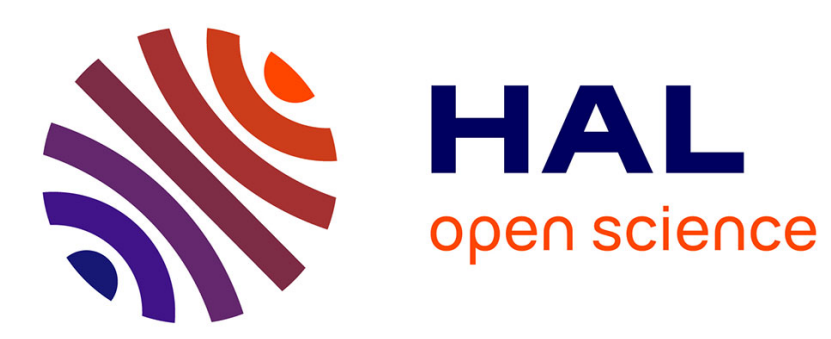

\title{
Evaluation of the Bone Status in High-Level Cyclists
}

Gérard Guillaume, Daniel Chappard, Maurice Audran

\section{To cite this version:}

Gérard Guillaume, Daniel Chappard, Maurice Audran. Evaluation of the Bone Status in High-Level Cyclists. Journal clinical Densitometry, 2012, 15 (1), pp.103-107. 10.1016/j.jocd.2011.08.001 . hal00840052

\section{HAL Id: hal-00840052 \\ https://hal.science/hal-00840052}

Submitted on 1 Jul 2013

HAL is a multi-disciplinary open access archive for the deposit and dissemination of scientific research documents, whether they are published or not. The documents may come from teaching and research institutions in France or abroad, or from public or private research centers.
L'archive ouverte pluridisciplinaire HAL, est destinée au dépôt et à la diffusion de documents scientifiques de niveau recherche, publiés ou non, émanant des établissements d'enseignement et de recherche français ou étrangers, des laboratoires publics ou privés. 


\title{
Evaluation of the Bone Status in High-Level Cyclists
}

\author{
Gérard GUILLAUME, ${ }^{1}$ Daniel CHAPPARD ${ }^{2}$ and Maurice AUDRAN ${ }^{2,3}$ \\ ${ }^{1}$ French Professional Cyclism Team, Paris, France; \\ ${ }^{2}$ INSERM, U 922-LHEA, IRIS-IBS Institut de Biologie en Santé, CHU Angers, Angers, \\ France \\ ${ }^{3}$ Department of Bone and Joint Disorders, UNAM, CHU Angers, Angers Cedex, France
}

e-mail : maaudran@ chu-angers.fr

Doi : 10.1016/j.jocd.2011.08.001.

Key words: highly trained cyclists; Bone Mineral Density ; IGF-I; Vitamin D.

\begin{abstract}
The purpose of this study was to evaluate the bone status in highly trained professional cyclists subjected to regular training and tough competitions. Bone mineral density (BMD) was measured at different regions of interest by dual X-ray absorptiometry and main biological parameters related to bone metabolism were obtained in 29 cyclists. Lumbar BMD was $0.94 \pm 0.01 \mathrm{~g} / \mathrm{cm}^{2}(Z$ score $=-1.28 \pm 0.07)$ and 1 cyclist out of 4 had and abnormally low value (Z-score <-2). The mean $Z$ score at the total femoral site was $-1.22 \pm 0.21$ and $45 \%$ of athletes had a Z-score <-2. All femoral neck BMD values were within normal boundaries. The lowest BMD Z-score were measured at the mid radius or $1 / 3$ proximal site with a mean Zscore of $-1.77 \pm 0.78$ but only 3 cyclists $(15 \%)$ had Z-scores <-2. Biochemical parameters of bone formation, (serum ostéocalcine, and alkaline phosphatase) were normal. Three cyclists had low 25(OH) vitamin D levels. Blood testosterone and TSH were in the normal range. IGF-I levels were in the normal range; however, a significant inverse correlation was found with lumbar BMD $(\mathrm{r}=0.495 ; \mathrm{p}=0.003)$. We confirm that cycling has no positive effect on BMD; BMD being often lower than in normal controls at the lumbar site; femoral BMD is less concerned. Absence of beneficial changes at the spine can be explained by biomechanical conditions related to the cyclists' position, reducing loading strains. It is necessary to pay greater attention to the bone status of high level athletes to prevent an increased risk of fractures.
\end{abstract}

\section{Introduction}

The effects of physical exercise on bone mass have been the subject of many studies, the results of which are largely determined by the type of exercise $(1 ; 2)$. It was thus observed that sports that generate weight bearing, with repeated impact loading have a more favorable effect than sports activities that do not, like swimming or cycling (1; 2). Bone density measurements can be very easily measured by a non-invasive method such as dual X-ray absorptiometry (DXA) applied at different sites of the skeleton: lumbar spine, proximal femur (femoral neck, total hip) as well as forearm (proximal and distal radius) (3; 4). DXA provides an areal bone mineral density (BMD) measurement with a good precision of 1 to $2 \%$ at the lumbar and femoral sites in young people. Radiation dose is very low $(0.5 \mu \mathrm{SV}$ at the forearm, 2 to $4 \mu \mathrm{SV}$ at the spine or femur) (5). In younger patients, before the age of $50 \mathrm{yr}$, results are expressed as $\mathrm{Z}$-score, in reference to age-and gender ethnically matched reference 
data, given by the manufacturer. Normal Z-scores values are comprised between -2 and +2 (SD); a Z-score value less than -2 (SD) defines a "low bone density". In post-menopausal women as well as in elderly in general, results are more often given as T-score in reference to sex peak bone mass measured in young matched subjects. The World health Organization has defined osteoporosis in post-menopausal women as a T-score value less than -2.5, but this does not strictly apply to young men (6). These outcomes are discussed in light of other works performed either in practitioners of the same sports activity, or other high level sports under different constraints.

Growth hormone (GH), as well as Insulin-like growth factors, and IGF-I in particular, exert anabolic effects on skeletal muscles, protein metabolism and lean body mass (7; 8). Bone and mineral metabolism is also partially regulated by GH directly and/or indirectly through IGF-I production, resulting in increased bone turnover as well as increased osteoblast number and function. GH (via IGF-I) stimulates also the renal 25-hydroxyvitamin D-1 alpha-hydroxylase activity and therefore enhances calcium and phosphate absorption in the intestine $(9 ; 10)$. We report the results of measurements of bone mineral density (BMD at the lumbar, femoral and forearm levels), in a large series of professional cyclists having a high training level and who were subjected to regular training and tough competitions (Tour de France).

\section{Subjects and Methods}

\section{Study population}

Professional cyclists $(n=29)$, from the same team, aged $26.5 \pm 5.3$ yrs, volunteered to get an evaluation of their bone status. In addition to the clinical exam (size, weight, BMI, sporting antecedents, medical history) the following data was collected:

The calcium intake, at distance from a competition, was evaluated by a validated questionnaire (11). BMD at the lumbar and femoral sites (total and trans-cervical) as well as at the radius, in 20 cyclists. Measurements were performed in the same densitometry center using a Hologic Discovery C device (Bedford, MA). Values were obtained in $\mathrm{g} / \mathrm{cm}^{2}$ and expressed as Z-score (in comparison with the values of normal subjects of the same age), according to the reference data given by the manufacturer. In vivo precision with this technique is less than $2 \%$ for the spine and hip measurements.

Biological parameters related to bone metabolism were obtained in 29 cyclists: serum calcium, phosphate and creatinine, alkaline phosphatase levels, serum osteocalcin, 25 hydroxyvitamin D, testosterone, IGF-I, TSH; all measurements were carried out in the same laboratory.

\section{Statistical analysis}

Statistical analysis was performed using the Systat ${ }^{\circledR}$ statistical software release 11 (Systat Software, Inc., San Jose, CA). Results were expressed as the mean \pm SD. Linear regression analysis were used to establish the relationship between BMD and biochemical values. Differences were considered as significant when $\mathrm{p}<0.05$.

\section{Results}

The general physical characteristics and training history of master cyclists are shown in Table I. The size and weight of our cyclists have been compared to data obtained in American highly trained male cyclists (12) and there was no significant difference (size: $181.3 \pm 4.7 \mathrm{~cm}$ in our series vs $178.4 \pm 5.2 \mathrm{~cm}$; weight $71.5 \pm 5 \mathrm{~kg} v s 71.9 \pm 6.4 \mathrm{~kg}$ ). The mean calcium intake was $897 \pm 158 \mathrm{mg} / \mathrm{d}$. Although we do not have BMD/BMC values for French subjects, 
because the anthropometric characteristics did not differ between American controls and our cyclists, we used the NHANES reference data (13).

BMD data at the different regions of interest were as follows and appear on Fig.1:

Lumbar BMD was $0.94 \pm 0.01 \mathrm{~g} / \mathrm{cm}^{2}$ corresponding to a $\mathrm{Z}$ score of $-1.28 \pm 0.07$ (Fig. 1 and 2). Five (25\%) runners had an abnormally low BMD characterized by Z-score <-2 (Fig. 2).

At the total femoral extremity, BMD was $0.89 \pm 0.05 \mathrm{~g} / \mathrm{cm}^{2}$, with a mean $\mathrm{Z}$ score of $-1.22 \pm 0.21$. At this site, BMC and surface area also appear on Fig. 1. All Z-score values were lower than 0 and 9/20 (45\%) had Z-score less than -2, corresponding to "low BMD" according to the International Society for Clinical Densitometry (ISCD) definition (Fig. 2).
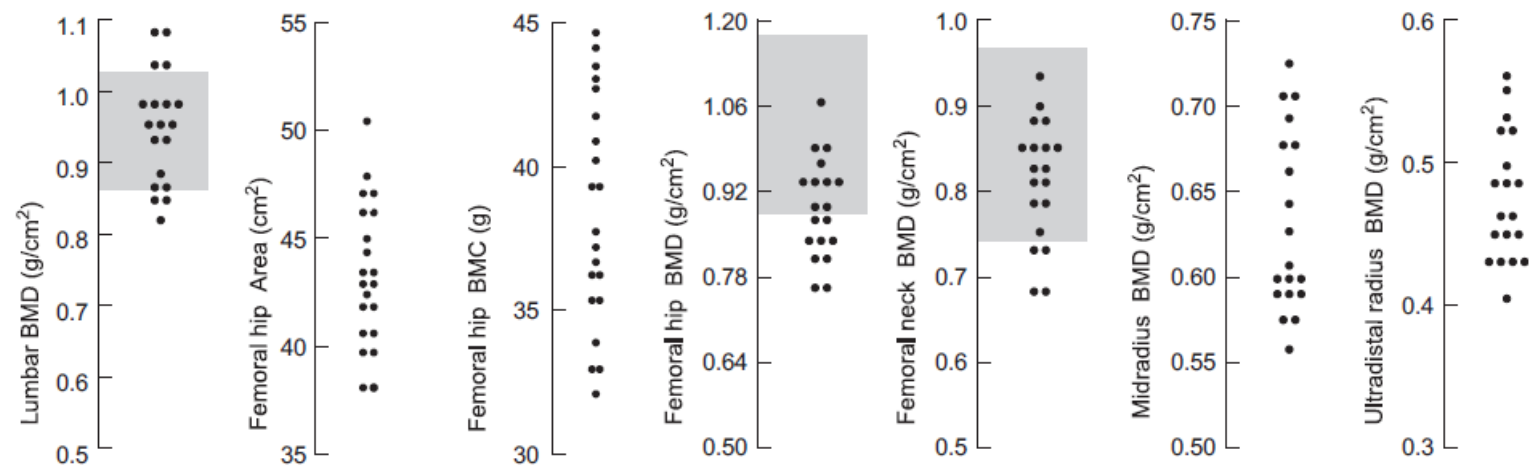

Figure 1. BMD values $\left(\mathrm{g} / \mathrm{cm}^{2}\right)$ at lumbar, femoral and radius sites in 20 highly trained. (Normal values are indicated at lumbar and femoral sites by shaded areas).
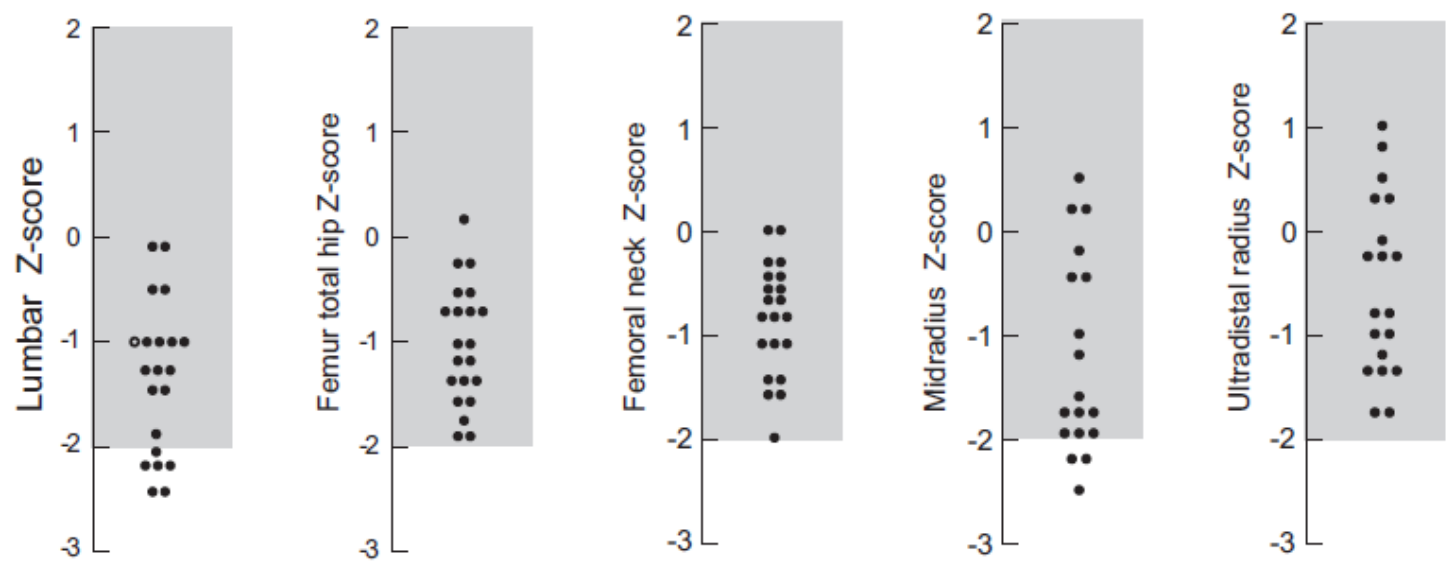

Figure 2. Z-score values at lumbar, femoral and radius sites in 20 highly trained cyclists. (Normal Z-score data are indicated by shaded areas).

Individual values of femoral neck BMD are shown on Figure 1. Mean femoral neck BMD was $0.81 \pm 0.08 \mathrm{~g} / \mathrm{cm}^{2}$, corresponding to a Z-score of $-1.21 \pm 0.42$. All BMD values were within normal boundaries, between -2 and +2 SD (Fig. 2).

The lowest values BMD Z-score were measured at the mid radius or $1 / 3$ proximal site (primarily cortical site), with a mean Z-score of $-1.77 \pm 0.78$ (Fig.2) but only 3 cyclists (15\%) had Z-scores less than -2 SD at this site.

Biological data, measured in 29 cyclists, are reported in Table II. Serum calcium and kidney function were in the normal range. Biochemical parameters of bone formation, (i.e. serum osteocalcin and alkaline phosphatase activity) were normal. Blood samplings for vitamin D measurements were obtained at different periods over the year. Mean 25(OH) vitamin D 
levels at $75 \mathrm{mmol} / \mathrm{L}$ corresponded to the current reference standard. Individual values ranged from $29 \mathrm{mmol} / \mathrm{L}$ for the lowest (corresponding to vitamin $\mathrm{D}$ deficiency) to $143 \mathrm{mmol} / \mathrm{L}$ for the highest. Three cyclists had $25(\mathrm{OH})$ vitamin D levels lower than $50 \mathrm{mmol} / \mathrm{L}$ (respectively $29,35,36 \mathrm{mmol} / \mathrm{L}$ ). Blood testosterone values shown in table II were in the normal range as well as TSH values. Mean IGF-I level was $210.4 \pm 79.6 \mu \mathrm{g} / \mathrm{l}$ (normal range: 232 to $385 \mu \mathrm{g} / \mathrm{l}$ ). A significant but inverse correlation was found between IGF-I levels and lumbar BMD $(\mathrm{r}=0.495 ; \mathrm{p}=0.003)$ (Fig. 3).

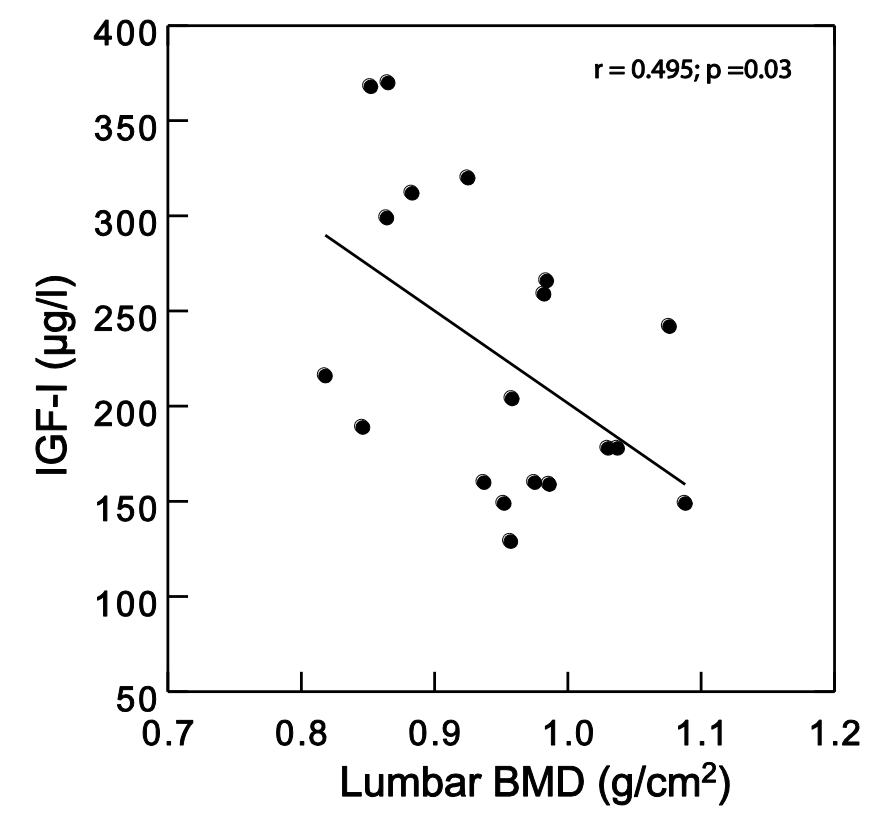

Figure 3. Correlation between lumbar BMD and IGF-I levels.

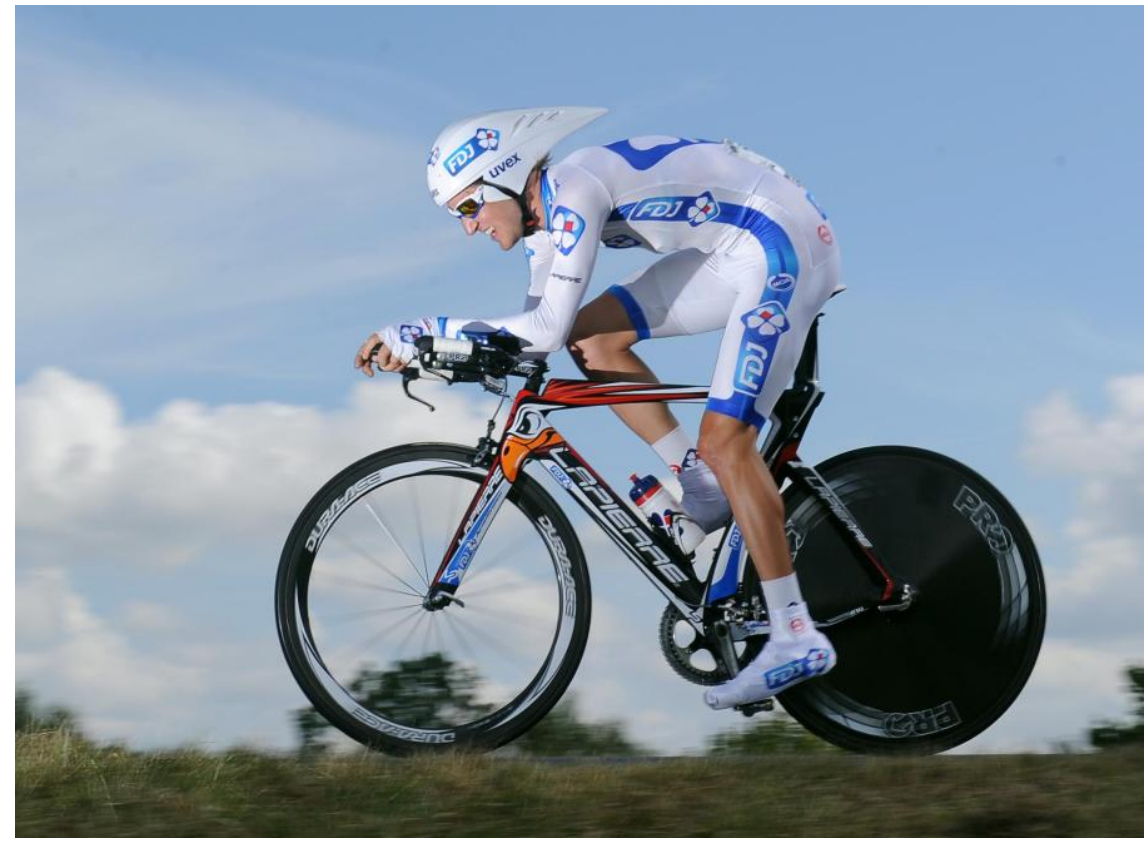

Figure 4. Typical position of a cyclist on his bicycle during the Tour de France. 


\section{Discussion}

Bone adapts permanently to the biomechanical, environmental and hormonal constraints to which it is subjected to by permanently balancing the activities of resorption and formation. Bone microarchitecture depends on the mechanical constraints which are exerted on skeleton (14); prolonged immobilization and weightlessness induce bone resorption. The beneficial effects of physical-activity on the skeleton have been well established $(15 ; 16)$; for instance, prevention of osteoporosis by physical activity has been suggested in women (17). The effects of high level sport training on bone may differ according to the specific constraints of the various activities practiced, to the amplitude and repetition of the constraints they induce, and to the bone sites on which load is applied. Cross-sectional studies in athletes report a positive effect of intense physical exercise on BMD (1). A traditional example is that of tennis players whose BMD is significantly increased on the dominant arm (18). A significant increase in BMD has also been reported in many other sports: soccer, volley ball, gymnastics (19). High impact, repetitive sports produce better results on lumbar BMD $(20 ; 21)$. The amplitude of strains has to be taken into account, more than their repetition. Athletes practicing resistance sports had a more positive effect on vertebral and axial bones than controls; those practicing an activity concerned with endurance had higher BMD than controls only at the lower limbs (19). As suggested by Rubin and Lanyon (22; 23), magnitude of loading may be more important than the number of cycles or repetition: runners have better lower lumbar and femoral BMD than gymnasts or controls because strains generated are about 10 to 12 times the body weight, while those from runners only approach 2 to 5 times the body weight (24).

Analysis of the bone status of these high level cyclists raises certain points which are not found in other sports. BMD measurements in these highly trained cyclist was found in the lower range as found by others $(12 ; 25)$. Although we do not have BMD/BMC values for French subjects, because the anthropometric characteristics did not differ between American controls and our subjects, we used the NHANES reference data (13). BMD measurement has been performed in internationally high-performance athletes of different disciplines; lumbar BMD of the high-performance weight lifters was greater than that of the controls by $24 \%$, while BMD of the lumbar spine in all endurance cyclists was significantly and surprisingly lower than that in the controls (26). Running is associated with increased bone density in the legs, whereas cycling is associated with a mild decrease in bone density in the spine (27); in athletes performing both sports, running was found to exert a stronger influence than cycling. In another study comparing lumbar and femoral BMD in former cyclists, young cyclists and non-athlete controls, the lowest values were measured in the former cyclists, $15 \%$ of them having one $\mathrm{T}$ score lower than 2.5 (12). In spite of the relatively fixed position of the cyclist on his bicycle, there are certainly strains and muscular tractions applied on the vertebrae, but strains are of low amplitude in comparison with other sports (Figure 4). Moreover, the horizontal distribution of the weight of the body along the vertebral axis during long hours has suggested that the spine is in a situation close to that of bedrest $(12 ; 28)$. In a study conducted over a 7-year period, there was a consistent pattern of lower BMD in cyclists compared to non-athletes at all bone sites measured (29). It has been reported than mountain cyclists have a higher BMD than non-road cyclists (30). In this series, only 4 cyclists were considered as climbers; the areal BMD did not differ $(p=0.25)$. A higher risk of low BMD was observed in those who spent many hours on their bicycle but were less assiduous in the muscledevelopment exercises during their career (28). It has therefore been suggested that coaches and health professionals interacting with cyclists need to promote alternative exercise. This observation was not verified in our study in which BMD in 3 cyclists regularly performing cyclocross in winter, (one classified in the top ten) had no better BMD values. Calcium 
intake, evaluated by a validated questionnaire, was in the same range as obtained in highly trained in 73 highly trained cyclists $(942 \pm 374 \mathrm{mg} / \mathrm{d} v s 897 \pm 158$ in the present series) (25).

In our study all measured parameters of bone metabolism were in the normal range. Mean $25(\mathrm{OH})$ vitamin D was normal; 3 cyclists had low values. Nevertheless, some modifications of calcium homeostasis have been described in athletes $(31 ; 32)$. After the Vuelta a España cycling race, lower levels of cortisol and testosterone were measured in cyclists, suggesting that the basal activity of the pineal gland, adrenal glands, and testis may be decreased after consecutive days of intense, long term exercise (33). Men suffering from hypogonadism have low BMD with disorganized trabeculae (34). In our study no significant hormonal anomaly of TSH was noted. IGF-I levels were in the normal range in our series of male cyclists. Acute endurance-type exercise increased serum GH and total IGF-I, both peaking at the end of exercise; however, free IGF-I did not change with exercise (35). Surprisingly, we observed in these highly trained athletes an inverse relationship between lumbar BMD and IGF-I levels.

In conclusion, our study was performed on a homogeneous group of young professional master cyclists, subjected to similar training. We confirm that cycling has no positive effect on BMD. At the lumbar site, the BMD is even often lower than in control populations of the same age and femoral BMD is less concerned. These results and particularly the absence of beneficial changes at the spine can be explained by biomechanical conditions related to the position of the cyclists; loading strains are less than in weight-bearing sports, more regular, and exerted in a horizontal axis. Biochemical markers of bone turnover and parameters of calcium homeostasis were in the normal range. Our data confirm previous results in professional master cyclists and underline the need to pay greater attention to the bone status of these athletes (28).

\section{References}

1. Morel J, Combe B, Francisco J, et al. 2001 Bone mineral density of 704 amateur sportsmen involved in different physical activities. Osteoporos Int 12:152-157.

2. Andreoli A, Monteleone M, Van Loan M, et al. 2001 Effects of different sports on bone density and muscle mass in highly trained athletes. Med Sci Sports Exerc 33:507-511.

3. Fogelman I, Blake GM. 2005 Bone densitometry: an update. Lancet 366:2068-2070.

4. Gluer CC, Engelke K, Lang TF, et al. 1995 Quantitative computed tomography (QCT) of the lumbar spine and appendicular skeleton. Eur J Radiol 20:173-178.

5. Blake GM, Naeem M, Boutros M. 2006 Comparison of effective dose to children and adults from dual X-ray absorptiometry examinations. Bone 38:935-942.

6. Kanis JA, Melton LJ, 3rd, Christiansen C, et al. 1994 The diagnosis of osteoporosis. J Bone Miner Res 9:1137-1141.

7. Gibney J, Healy ML, Sonksen PH. 2007 The growth hormone/insulin-like growth factor-I axis in exercise and sport. Endocr Rev 28:603-624.

8. Woodhouse LJ, Mukherjee A, Shalet SM, et al. 2006 The influence of growth hormone status on physical impairments, functional limitations, and health-related quality of life in adults. Endocr Rev 27:287-317.

9. Bianda T, Glatz Y, Bouillon R, et al. 1998 Effects of short-term insulin-like growth factor-I (IGF-I) or growth hormone $(\mathrm{GH})$ treatment on bone metabolism and on production of 1,25-dihydroxycholecalciferol in GH-deficient adults. J Clin Endocrinol Metab 83:81-87. 
10. Rosen CJ. 2003 Insulin-like growth factor I and calcium balance: evolving concepts of an evolutionary process. Endocrinology 144:4679-4681.

11. Fardellone P, Sebert JL, Bouraya M, et al. 1991 [Evaluation of the calcium content of diet by frequential self-questionnaire]. Rev Rhum Mal Osteoartic 58:99-103.

12. Nichols JF, Palmer JE, Levy SS. 2003 Low bone mineral density in highly trained male master cyclists. Osteoporos Int 14:644-649.

13. Looker AC, Wahner HW, Dunn WL, et al. 1998 Updated data on proximal femur bone mineral levels of US adults. Osteoporos Int 8:468-489.

14. Chappard D, Baslé MF, Legrand E, et al. 2008 Trabecular bone microarchitecture: a review. Morphologie 92:162-170.

15. Maimoun L, Mariano-Goulart D, Couret I, et al. 2004 Effects of physical activities that induce moderate external loading on bone metabolism in male athletes. J Sports Sci 22:875-883.

16. Creighton DL, Morgan AL, Boardley D, et al. 2001 Weight-bearing exercise and markers of bone turnover in female athletes. J Appl Physiol 90:565-570.

17. Borer KT. 2005 Physical activity in the prevention and amelioration of osteoporosis in women: interaction of mechanical, hormonal and dietary factors. Sports Med 35:779830.

18. Huddleston AL, Rockwell D, Kulund DN, et al. 1980 Bone mass in lifetime tennis athletes. Jama 244:1107-1109.

19. Bennell KL, Malcolm SA, Khan KM, et al. 1997 Bone mass and bone turnover in power athletes, endurance athletes, and controls: a 12-month longitudinal study. Bone 20:477-484.

20. Jacobson PC, Beaver W, Grubb SA, et al. 1984 Bone density in women: college athletes and older athletic women. J Orthop Res 2:328-332.

21. Taaffe DR, Snow-Harter C, Connolly DA, et al. 1995 Differential effects of swimming versus weight-bearing activity on bone mineral status of eumenorrheic athletes. J Bone Miner Res 10:586-593.

22. Rubin CT. 1984 Skeletal strain and the functional significance of bone architecture. Calcif Tissue Int 36 Suppl 1:S11-18.

23. Lanyon LE, Rubin CT. 1984 Static vs dynamic loads as an influence on bone remodelling. J Biomech 17:897-905.

24. Robinson TL, Snow-Harter C, Taaffe DR, et al. 1995 Gymnasts exhibit higher bone mass than runners despite similar prevalence of amenorrhea and oligomenorrhea. $\mathrm{J}$ Bone Miner Res 10:26-35.

25. Medelli J, Shabani M, Lounana J, et al. 2009 Low bone mineral density and calcium intake in elite cyclists. J Sports Med Phys Fitness 49:44-53.

26. Sabo D, Bernd L, Pfeil J, et al. 1996 Bone quality in the lumbar spine in highperformance athletes. Eur Spine J 5:258-263.

27. Stewart AD, Hannan J. 2000 Total and regional bone density in male runners, cyclists, and controls. Med Sci Sports Exerc 32:1373-1377.

28. Medelli J, Lounana J, Menuet JJ, et al. 2009 Is osteopenia a health risk in professional cyclists? J Clin Densitom 12:28-34.

29. Nichols JF, Rauh MJ. 2011 Longitudinal changes in bone mineral density in male master cyclists and nonathletes. J Strength Cond Res 25:727-734.

30. Warner SE, Shaw JM, Dalsky GP. 2002 Bone mineral density of competitive male mountain and road cyclists. Bone 30:281-286.

31. Maimoun L, Sultan C. 2009 Effect of physical activity on calcium homeostasis and calciotropic hormones: a review. Calcif Tissue Int 85:277-286. 
32. Bell NH, Godsen RN, Henry DP, et al. 1988 The effects of muscle-building exercise on vitamin D and mineral metabolism. J Bone Miner Res 3:369-373.

33. Lucia A, Diaz B, Hoyos J, et al. 2001 Hormone levels of world class cyclists during the Tour of Spain stage race. Br J Sports Med 35:424-430.

34. Audran M, Chappard D, Legrand E, et al. 2001 Bone microarchitecture and bone fragility in men: DXA and histomorphometry in humans and in the orchidectomized rat model. Calcif Tissue Int 69:214-217.

35. Wallace JD, Cuneo RC, Baxter R, et al. 1999 Responses of the growth hormone (GH) and insulin-like growth factor axis to exercise, GH administration, and GH withdrawal in trained adult males: a potential test for GH abuse in sport. J Clin Endocrinol Metab 84:3591-3601. 